\title{
Advanced training concept for the coal mining industry in the region
}

\author{
Natalia Kasatkina ${ }^{1}$, Olga Krasnoshlykova ${ }^{2, *}$,Elena Rudneva $^{3}$, Tatiana Churekova ${ }^{4}$, and \\ Albina Levanova ${ }^{5}$ \\ ${ }^{1}$ Kuzbass Regional Institute for Further Training of Educators, Head of the Pedagogy Research \\ Laboratory, 650070, 3 Zauzelkova st., Kemerovo, Russian Federation \\ ${ }^{2}$ Kuzbass Regional Institute for Further Training of Educators, Rector, 650070, 3 Zauzelkova st., \\ Kemerovo, Russian Federation \\ ${ }^{3}$ Kemerovo State University, Head of Interuniversity Department of General and University Pedagogy, \\ 6500006 Krasnaya st., Kemerovo, Russian Federation \\ ${ }^{4}$ Kemerovo State University of Culture and the Arts, Head of the Department of Pedagogy, 65005617 \\ Voroshilova st., Kemerovo, Russian Federation \\ ${ }^{5}$ Kemerovo State University, Department of Foreign Languages in Professional Communication, \\ 6500006 Krasnaya st., Kemerovo, Russian Federation
}

\begin{abstract}
The article presents the concept of advanced training of personnel for the coal mining industry in the conditions of an education and technology cluster associated with the training of personnel for the region, professionally mobile, ready to implement life and professional selfdetermination. A clear understanding of a wide scope of theory, practice and critique in relation to learning environments prompts the further development of education and technology clusters aimed at integrating and concentrating the activities of educational institutions of general secondary, secondary vocational and higher education in collaboration with coalmining industry enterprises for socio-economic development of the region.
\end{abstract}

\section{Introduction}

The domestic education system, which in recent years has undergone significant structural and substantive reforms in response to various globalized policy drivers and new education delivery technologies, is directed at improving the quality of training for the coal mining industry in the region in the new changing socio-economic conditions.

Education clusters have a special role to play in modernizing the vocational education system, since it is in the context of education and technology clusters that educational organizations and their social partners have been given the opportunity to interact in actual social relations and transforming economic environment. This interaction makes it possible to effectively address both the organization of the training process for future professionals and changes in the content of vocational guidance work, which, in turn, contributes to the implementation of the concept of advanced training for industry.

\footnotetext{
* Corresponding author: ipk@,kuz-edu.ru
} 
Institutions of general secondary education (hereinafter referred to as GSEI), vocational education organizations - colleges, technical colleges (hereinafter referred to as VTEI) and higher education institutions (hereinafter referred to as HE) train specialists who currently do not fully meet the challenges of dynamically changing requirements for the labor market and cannot stand up to better-trained professionals. Based on the results of our research we consider it necessary to underline the increasing interest and importance of current relative studies devoted to the cluster theory and practice in relation to learning environments and the adoption of innovative solutions for utilization of cluster policy to improve socio-economic development of the region.

\section{Results and Discussion}

\subsection{Goals and objectives of the study}

In the course of our research, we identified the reasons for such insufficiencies in training: - the lack of awareness on the part of the teaching staff of educational organizations of the nature and consequences of the social and economic processes taking place in industry in the context of globalization and the adoption of information technology, which require a fundamental rethinking of the mission, the tasks and responsibilities of educational organizations to graduates and to the State;

- the deficiency of a clear vision among the teaching staff of educational organizations of the mechanisms for interaction between educational institutions and social partners in addressing the challenges of training for the region, in particular, the organization of joint work to resolve mutually beneficial issues relating to the modernization of vocational guidance, with a focus on the requirements of modern production; the organization of effective practices for students in terms of their real training in vocational and higher education institutions;

- the failure to provide sufficient vocational guidance exacerbates the problem of the professional guidance for VTEI graduates, which inevitably arises in the context of objective changes in the structure of personnel training for the region, etc...

- the socio-economic situation in the region, when professional organizations of secondary and higher education, opened in the XX century to meet the needs of educational institutions, have lost their importance due to the material and technical inconsistency with the new requirements of the organization of the educational process and the requirements of modern production, etc.

Our analysis has proved that the issue of organizing the education and technology cluster currently requires special attention in pedagogical science.

The goal of the study is: scientific substantiation and experimental verification of the main directions of activity of the education and technology cluster which provides training for the coal mining industry in collaboration with educational, professional and higher education organizations of the region, functioning within the regional labor market system.

Research Objectives are the following.

To identify the current trends in the establishment of an education and technology cluster (joint work of general education organizations, professional (technical colleges, technical schools and universities) and higher education organizations with employers using innovative technologies, networking, motivation and value orientations, advanced training of specialists of educational organizations, joint training activities with employers from organizations of the coal mining industry in the region.

To determine the features of the interaction of educational organizations with employers and social partners in the formation of vocation self-determination of students in educational organizations, using new organizational and legal forms of such interaction (social 
partnership, network interaction, public-private partnership, education and technology cluster).

To define and implement the content of the activities of the education and technology cluster, providing training of future specialists for the coal-mining enterprises in the region from students of educational and professional organizations, taking into account the needs of social partners based on various forms of cooperation among actors of the education and technology cluster [1].

To implement, design and further pilot-test key activities in the conditions of the education and technology cluster for the training of personnel for the coal mining industry of the region among students.

Our research has shown that the tendency of establishing clusters of different kinds, as well as the education and technology clusters, is currently given special attention and manifold discussions in science [2-5].

\subsection{Methodology for the establishment of an education and technology cluster}

The first clusters as objects of interconnected organizations on a limited territory have been known since the beginning of the XVIII century. Studies of spatial competitiveness in the context of cluster theory are associated with the name of M. Porter (1998), who considered the cluster approach as one of the most effective mechanisms for the structural development of the economy, claiming that economic activities are inclusive in social activities; that 'social interconnection binds actors together' [6]. This is confirmed by recent studies showing that particularly in regional and rural areas, significantly more innovation occurs in communities which have stronger inter-personal networks: P. Merlevede, 2014 [7]; C. Ketels, 2018 [8]; L. Benade, M. Jackson, 2018 [9].

In the conditions of developing market economy and innovative socio-economic processes in modern Russia, researchers distinguish the following types of clusters being created in the country:

1."University-oriented" clusters. These include innovation clusters, which create a large concentration of the intellectual forces of universities on the local territory. This allows to ensure the formation of an adequate training environment favorable for innovation.

2. Multi-level clusters, which are vertically integrated structures of the « vocational education organizations - higher education - employer» type.

3. Pre-university level clusters, which consist of specialized multi-level institutions created on the basis of GSEI, VTEI and graduating qualified middle-level personnel for the local industry.

As a mechanism for solving the tasks set for the education system, we considered the creation of education and technology clusters on the basis of general education, professional and higher educational organizations as a means to facilitate formation of a practicallyoriented educational space conducive to learning based on the integration and interaction with employers and social partners $[10 ; 11]$.

The formation of education clusters is based on three main processes:

- "horizontal integration" of educational organizations of general secondary education and educational institutions of secondary vocational education (i.e., organizations of the same level);

- "vertical integration" of general education institutions, organizations of secondary vocational education and institutions of higher education, as well as industrial organizations (i.e., organizations of different levels);

- "complex integration" ("horizontal" and "vertical") - the creation of multi-level educational institutions and their networks, educational consortia, etc. 
The core of the education and technology cluster, in our view, is an educational organization of vocational training (a technical school, college or an industrial enterprise), an organization of higher or additional education (adult organizations) which possesses an innovative potential, allowing to position itself as a center capable of strengthening the processes of integrating innovative activity within the territory of Kemerovo region.

\subsection{Resources for setting up an education and technology cluster}

In the course of our research, as an imperative for the creation of an education and technology cluster, we considered the following:

- presence in the region of a large leading university that trains personnel for the system of the coal mining industry in the region, in some cases, subordinating to a federal or regional special educational zone;

- presence of large industrial production complexes in the region, in some cases under the authority of a federal or regional special economic zone;

- existence of actively developing regional employers' associations;

- experience of social partnership with employers in the regional system of professional cooperation;

- immediate need in training personnel for the coal mining and metallurgical industries of the region;

- experience of the regional professional system in social partnership with employers. The emerging development of the education and technology cluster came at a time when the problems of regional educational organizations and industrial enterprises were being addressed through approaches that were not always very effective.

These requirements are presently being complied with in the created clusters and beyond them, as there are urgent personnel needs for the coal mining enterprises.

The emergence of new areas opens up prospects for creating new jobs, whose specialists will be able to compete in the labor market, which means that they should be able to receive highly qualified professional training in universities and professional educational organizations, upgrade their skills and undergo retraining if necessary.

The administration of Kemerovo region, which is one of the leading centers for coal mining industry in Russia, recognizes the education and technology cluster idea beneficial for the improvement of professional training for coal mining enterprises in the region. The regional cluster research programs mobilized the key educational and industrial actors in a very effective way making studies practically oriented. A regional council on personnel policy has been set up on the local government initiative, which deals with issues of interaction and cooperation of the institutions of general secondary, vocational and higher education and industrial establishments. It introduced the system of direct contracts between general secondary, vocational and higher education institutions and industrial organizations in the region as a mandatory element of regional personnel policy. In this case, not only are the interests of employers, general secondary schools and secondary vocational and higher education establishments sought together, but joint activities are also defined to solve the region's pressing social and economic needs.

To resolve this problem, as the experience of the pilot-test activities of the education and technology clusters for the training personnel for the coal mining industry in the region has shown, is the further development and formation of regional, municipal education and technology clusters based on long-term strategic planning mechanisms and the broad integration of educational and industrial spheres, as a form of social partnership developing a social environment. 


\subsection{Pedagogical Model of an Education and Technology Cluster}

The effectiveness of the education and technology cluster for the development of the region is evaluated by forecasting the need for coal-mining personnel for the region; creation of an active base of cluster cooperation as a form of social partnership; formation of the social environment, that makes maximum use of the potential (resource) of social partners participants of the education and technology cluster.

In the course of the research, we have developed a pedagogical model of personnel training for the coal mining industry in the region in the conditions of the education and technology cluster. The presented model, being multidimensional and structurally functional, comprises five structural components (targeted, methodological, content, operational and evaluative).

The target component of the implementation of the pedagogical model is oriented towards the fulfillment of state and social personnel orders.

The methodological component relates to the implementation of the principles of interaction and the relationship of the actors who combine their resources; the pooling of the efforts and resources of two or more equal partners; the contractual form of interaction, which includes the sharing of responsibilities among the partners, and interactive nature of cooperation.

The content component is related to the establishment of an education and technology cluster in the territory, performing the function of training personnel on the basis of networking with educational organizations in the region. Resource centers together with employers provide professional information, coordinate the conduct of professional tests and professional competitions, carry out psychological and pedagogical support for personnel training for coal mining enterprises in the region, including the adaptation of graduates of GSEI, VTEI and HE to the regional labor market.

The operational component makes it possible to assess the level of theoretical knowledge acquired by the trainees and the level of formation of professional skills, the skills and competences of the future profession. Our research has made it possible to ascertain that, in the course of the activities of the education and technology cluster, the number of modules in the cluster model can be increased or reduced by implementing new areas of educational activity in general secondary, secondary vocational and higher education institutions.

The evaluative component summarizes the solution to the issue of advanced professional training for the coal mining industry of the region in the context of the education and technology cluster, ensuring the necessary orientation of the vocational self-determination of learners on the basis of training quality criteria and indicators for the quality of VTEI and HE graduates, the level of formation of professionally significant competencies demanded by the region; the level of employment of graduates; and the level of formation of personal qualities of trainees: such as self-esteem, self-organization, self-control [12].

\section{Conclusion}

Thus, the advanced personnel training concept for the coal mining industry in the region, i.e. the creation of the education and technology clusters that provide quality training, is, in our view, an instrument for innovative development based on an awareness of the value of participation of the actors in the real education sector and industry. This approach expands methods and forms of interaction based on the integration of resources into one territory of general education organizations, vocational and higher educational institutions and social partners, who jointly address the challenge of improving the quality of training of future professionals for the region's human resources needs by actors in the real education sector 
and coal mining enterprises and expands the modes and forms of interaction among social partners in the regional labor market.

The basic idea and main advantage of the social partnership in the education and technology cluster makes it possible to have an effective partnership of different and useful actors, who individually have limited resources, therefore, it can be argued with good reason that the further scientific development and practical support of this area of research will solve the problems of preparing young people for a real choice of a professional path and solve the needs for qualified and able to compete professionals.

\section{References}

1. RF Government, On the Program for the Development of the Coal Industry of the Russian Federation for the Period up to 2030 (RFG, Moscow, 2014)

2. Malmberg, P. Maskell, Environment and Planning, A34, 429-449 (2002)

3. N.W. Ketelhohn, Journal of Economic Geography, 6(5), 679-699 (2006)

4. T. Reve, Journal of Competiveness, 1(1), 63-76 (2011)

5. F. Huber, Journal of Economic Geography, 12(1), 107-126 (2012)

6. M.E. Porter, Harvard Business Review, 76, 77-90 (1998)

7. P. Merlevede, Talent Management: A Focus on Excellence. Managing Human Resources in a Knowledge Economy (Bookboon, London, 2014)

8. C. Ketels, Regional competitiveness and Clusters: Cluster Mapping: Creating the Knowledge Infrastructure for Cluster-Based Economic Development Efforts (BCG Henderson Institute, Boston, 2018)

9. L. Benade, M. Jackson, Transforming Education: Design and Governance in Global Contexts (Springer, New York, 2018)

10. L. Nota, L.Ferrari, V.S.H. Solberg, S. Soresi, Journal of Career Assessment, 15, 181-193 (2007)

11. G.C. Gonzalez, R. Singh, K. Rita, D.S. Ortiz, Energy-Sector Workforce Development in Southwestern Pennsylvania. Aligning Education and Training with Innovation and Needed Skills (EAPL, Philadelphia, 2014)

12. J.A. Athanasou, R. Van Esbroeck, International Handbook of Career Guidance -2018. URL: https://link.springer.com/book/10.1007/978-1-4020-6230-8/ 